\title{
Research on Virtual Enterprise Market Demand Forecast Model Based on Theory of Markov Chain
}

\author{
Zhang Tianrui, Su Yingying, Dong Hai, Liang Di \\ School of Mechanical Engineering \\ Shenyang University, SYU \\ Shenyang, China \\ tianjiangruixue@126.com
}

\begin{abstract}
It was found that market demand was the critical factor for the uncertainty of virtual enterprise by the summarizing of the form of virtual enterprise(VE) supply chain and the analyzing of the uncertainty of the virtual enterprise supply chain. The market demand forecasting model based on Markov chain was established, aiming at the uncertainty of market demand. And it was used into the practical example to prove the feasibility of the mathematical model.
\end{abstract}

Keywords-virtual enterprise; supply chain; theory of Markov chain; uncertainty; market demand

\section{INTRODUCTION}

Virtual enterprise supply chain is a dynamic supply chain formed by the enterprise partners based on technical support and service provider with special information service center. Production manufacturing mode of JIT (Just In Time) should be integrated into the virtual enterprise supply chain management ${ }^{[1-2]}$. JIT is an advanced manufacturing mode improved the production efficiency, which refers to the order as a driver, via spectaculars, using pull the supply, production, sales closely together, greatly reduced the material reserves, cost of inventory and in products.

Virtual enterprises is facing a rapidly changing market, as a result uncertainty affecting the operation of virtual enterprise moment by moment ${ }^{[3-4]}$. Thus the key problems of the virtual enterprise supply chain modeling and optimization is to overcome the interference of uncertainty on the virtual enterprise supply chain. However, the uncertainty faced by virtual enterprise largely depends on the uncertainty of market demand. Therefore, it is necessary to establish a reliable, accurate market prediction model.

\section{UNCERTAINTY AND COMPOSING FORM OF VE SUPPLY CHAIN}

\section{A. Uncertainty of Virtual Enterprise Supply Chain}

Uncertainty $^{[5]}$ refers that the research subjects are lack of the determined nature. The research subjects may have a certain regularity, truthfulness and completeness, but at the

Liaoning Dr. Research Start-up Foundation (20150192), Liaoning Natural Science Foundation Project (2016010521301, 2016010513-301). same time is not sure. The uncertainty in supply chain is the uncertainty that existing in the supply chain system, effecting on the performance of the supply chain directly, controllable and administrable. The uncertainty of virtual enterprise supply chain derived from the followed two aspects mainly: the uncertainty of customer demand and the uncertainty of supply chain members ${ }^{[6]}$.

\section{B. Composing Form of Virtual Enterprise Supply Chain}

The virtual enterprise supply chain is composed through the core enterprise as the core, so it doesn't exist the mushy supply chain form mesh without core enterprise. According to the construction, the supply chain can be divided into three types including star type, chain type and hybrid type ${ }^{[7-8]}$. Their structure figures are shown as figure 1-3.

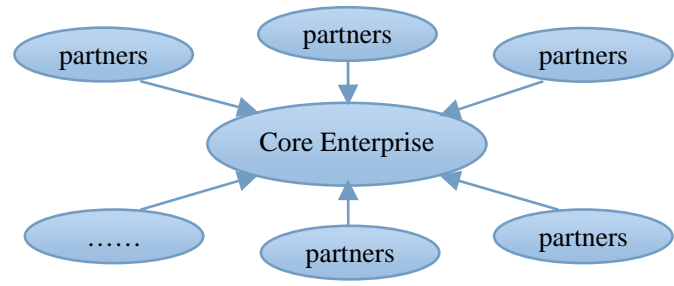

Fig. 1. Supply chain model of star type

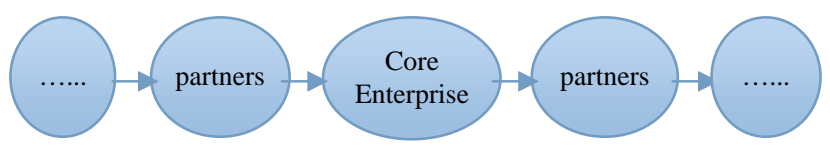

Fig. 2. Supply chain model of chain type

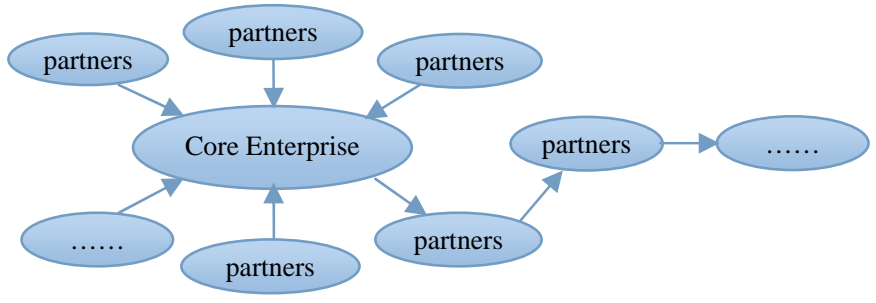

Fig. 3. Supply chain model of hybrid type 


\section{MARKET Demand Forecasting Model BASED ON MARKOV}

\section{A. Market demand forecast method}

Market forecast is the key areas of marketing research, the current prediction method are many, twenty or thirty kinds of the traditional prediction methods can be roughly classified into three kinds ${ }^{[9]}$ : judgment method, also called qualitative prediction method; time series analysis method, also called history extension method; causal analysis, also called a correlation analysis. The comparison of various prediction methods was such as shown in table I .

TABLE I. PREDICTION METHODS COMPARISON

\begin{tabular}{|l|l|l|l|}
\hline \multicolumn{1}{|c|}{ Methods } & \multicolumn{1}{|c|}{$\begin{array}{c}\text { Least } \\
\text { Required Data }\end{array}$} & Form of data & $\begin{array}{l}\text { Interval Between } \\
\text { Data }\end{array}$ \\
\hline $\begin{array}{l}\text { Simple exponential } \\
\text { smooth model }\end{array}$ & $5-10$ & Equally spaced & Short interval \\
\hline $\begin{array}{l}\text { Holt's exponential } \\
\text { smooth model }\end{array}$ & $10-15$ & Same tendency & $\begin{array}{l}\text { Short or middle } \\
\text { interval }\end{array}$ \\
\hline $\begin{array}{l}\text { Winter's exponential } \\
\text { smooth model }\end{array}$ & At least 5 & $\begin{array}{l}\text { Same tendency } \\
\text { with regularity }\end{array}$ & $\begin{array}{l}\text { Short or middle } \\
\text { interval }\end{array}$ \\
\hline $\begin{array}{l}\text { Regression analysis } \\
\text { method }\end{array}$ & 10 or at least 20 & $\begin{array}{l}\text { Same tendency } \\
\text { with regularity }\end{array}$ & $\begin{array}{l}\text { Short or middle } \\
\text { interval }\end{array}$ \\
\hline $\begin{array}{l}\text { Causal regression } \\
\text { method }\end{array}$ & At least 10 & $\begin{array}{l}\text { Mixed with } \\
\text { various forms }\end{array}$ & $\begin{array}{l}\text { Short, middle and } \\
\text { long interval }\end{array}$ \\
\hline $\begin{array}{l}\text { Time sequence } \\
\text { compression method }\end{array}$ & 2 peaks above & $\begin{array}{l}\text { Same tendency } \\
\text { with regularity }\end{array}$ & $\begin{array}{l}\text { Short or middle } \\
\text { interval }\end{array}$ \\
\hline Box Jenkins method & At least 50 & Equally spaced & $\begin{array}{l}\text { Short, middle and } \\
\text { long interval }\end{array}$ \\
\hline Markov method & $5-10$ or above & Equally spaced & $\begin{array}{l}\text { Short, middle and } \\
\text { long interval }\end{array}$ \\
\hline
\end{tabular}

B. Markov chain theory and model

- Markov chain theory ${ }^{[10]}$

There were much such phenomena in the reality world: A particular system was in the condition that it had been known, it was only related to now that the condition of the future moment of the system was, but it had not direct relationship to the past history. This was math model which can describe the kind of stochastic phenomena called Markov model.

Definition 1 If $\left\{\xi_{n}, n=1,2, \cdots\right\}$ was a stochastic sequence, state space $E$ was limited or countable set, for any positive integer $m, n$,if $i, j, i_{k} \in E(k=1,2, \cdots, n-1)$, if satisfied:

$$
\begin{aligned}
& P\left\{\xi_{n+m}=j \mid \xi_{n}=i, \xi_{n-1}=i_{n-1}, \cdots, \xi_{1}=i_{1}\right\} \\
= & P\left\{\xi_{n+m}=j \mid \xi_{n}=i\right\}
\end{aligned}
$$

Then $\left\{\xi_{n}, n=1,2, \cdots\right\}$ was called a Markov chain, actually, it could be proved that if equation (1) was set up for $m=1$, then it would be set up for $m$ which was a positive integers. So, if only $m=1$, equation (1) was set up, then it would be said that the stochastic sequence $\left\{\xi_{n}, n=1,2, \cdots\right\}$ had Markov property, and $\left\{\xi_{n}, n=1,2, \cdots\right\}$ was a Markov chain.
Definition $2^{[10]}$ if $\left\{\xi_{n}, n=1,2, \cdots\right\}$ was a Markov chain, if the conditional probability of the right side of the equation (1) had no relationship to the $n$, then:

$$
P\left\{\xi_{n+m}=j \mid \xi_{n}=i\right\}=P_{i j}(m)
$$

So $\left\{\xi_{n}, n=1,2, \cdots\right\}$ was called Time Markov chains. Then $P_{i j}(m)$ was transfer probability that system state i was via $\mathrm{m}$ intervals (or m steps) changing the state to $j$. It meat that: the transfer probability which the system was from state i to the state of $j$ only relied on the length of the time intervals rather than the moment of the start.

Definition 3 For a Markov chain $\left\{\xi_{n}, n=1,2, \cdots\right\}$, the matrix $P(m)=P_{i j}(m)$ which composed with $P_{i j}(m)$ the transfer probability with $m$ steps was called the $m$ steps of Markov chains transfer matrix. When $m=1$, marked $P(1)=P$ was called one steps of Markov chain transfer matrix, short for transfer matrix. They had the following three basic properties:

For all, $i, j \in E, 0 \leq P_{i j}(m) \leq 1$
For all, $i \in E, \sum_{j \in E} P_{i j}(m)=1$

For all, $i, j \in E, P_{i j}(m)=\delta_{i j}=\left\{\begin{array}{c}1, \text { when } i=j \\ 0, \text { when } i \neq j\end{array}\right.$

If $\left\{X_{m}, m \in T\right\}$ was homogenous Markov chain, then:

$$
P_{m}=P_{1} P^{m-1}(m>1)
$$

When the practical problem could be described by Markov chain, the first thing is to ensure its space state and the lumped parameter and then ensure its one step transfer probability. To make sure the probability it could be found in the problem inherent law, the past experience and the observation data.

- Markov chain forecast model ${ }^{[11]}$

As Markov process is a random process, it could be described the system transfer possibility which was from one state to another.

1) The probability vector. All the vectors were line vector in the model. As the variate had directivity in the Markov chain, meanwhile it was random that the vector changes, so it was needed to be described by probability ${ }^{[11]}$. If $P_{0}$ was probability vector, And the general formula of the probability vector is: $P_{0}=\left(\begin{array}{lllll}a_{1} & a_{2} & a_{3} & \cdots & a_{n}\end{array}\right)$.

2) The probability matrix. The matrix was composed by probability vector. One matrix satisfied the conditions of the probability matrix: All the elements would be equal and greater than 0; All the elements summed up in each line are equal to 1 ; The numbers of the rows and lines are equal.

3) The transfer matrix. Probability matrix could be used some related transfer state, and called the probability matrix was transfer matrix. Its significance lies in the things in the process of Markov chain from one state into another state transition. If the transfer state matrix could be expressed 
transfer state $P$, The $P$ is for transition probability matrix can be expressed as:

$$
P=\left[\begin{array}{cccc}
P_{11} & P_{12} & \cdots & P_{1 n} \\
P_{21} & P_{22} & \cdots & P_{2 n} \\
\vdots & \vdots & \ddots & \vdots \\
P_{n 1} & P_{n 2} & \cdots & P_{n n}
\end{array}\right]
$$

Then took it into the general predicted expression, it can be found from the Markov prediction mathematical model:

$$
P_{n}=\left(\begin{array}{lllll}
a_{1} & a_{2} & a_{3} & \cdots & a_{n}
\end{array}\right)\left[\begin{array}{cccc}
P_{11} & P_{12} & \cdots & P_{1 n} \\
P_{21} & P_{22} & \cdots & P_{2 n} \\
\vdots & \vdots & \ddots & \vdots \\
P_{n 1} & P_{n 2} & \cdots & P_{n n}
\end{array}\right]^{n-1}
$$

\section{APPLICATION EXAmple ANALYsis}

Xiaomi Tech (full name is Beijing millet technology co., LTD) is a typically virtual enterprise. Its parts were supplied by foxconn which provided goods for the Iphone, Motorola brand. And mobile phones were produced by Yingda foundry. Mobile phone operating system adopted the MIUI operating system which was independently researched and developed by millet company ,and mobile phones were sold through ecommerce platforms such as Vancl, Letao etc.

According to the market demand of millet company smart phone, the paper applied the prediction model that was mentioned above to predict and test the model. The sales of Millet mobile phone in some district of Beijing was shown in table II during October 2011 to February 2012, total 16 weeks.

TABLE II. SALES Statistics AND Assessment of State of Millet MOBILE PHONE

\begin{tabular}{|c|c|c|}
\hline Time(week) & Sale Quantity Q & State \\
\hline 1 & 210 & 1 \\
\hline 2 & 240 & 1 \\
\hline 3 & 400 & 2 \\
\hline 4 & 516 & 3 \\
\hline 5 & 408 & 2 \\
\hline 6 & 320 & 4 \\
\hline 7 & 620 & 3 \\
\hline 8 & 501 & 1 \\
\hline 9 & 550 & 2 \\
\hline 10 & 200 & 4 \\
\hline 11 & 321 & 3 \\
\hline 12 & 705 & 4 \\
\hline 13 & 520 & 2 \\
\hline 14 & 601 & 3 \\
\hline 15 & 304 & 2 \\
\hline 16 & 486 & 2 \\
\hline
\end{tabular}

- Constraint
When $Q<300$, the sales belonged to a very poor situation, directed by 1 .

When $300 \leq Q<450$, the sales belonged to a medium situation, directed by 2 .

When $450 \leq Q<600$, the sales belonged to a good situation, directed by 3 .

When $600 \leq Q$, the sales belonged to an excellent situation, directed by 4 .

According to the sales situation of Millet company in the 16th week, it was viable to predict the sales situation in the 17 th week. It could be seen that the randomness is great from the sales table above. Due to the effect of product quality and managerial and administrative expertise, there would be many random factors. So it was appropriate to use the Markov chain to predict the problem.

- Calculate the initial probability $P_{i}$

When belonged to statuses"1", points $W_{1}=3$.

When belonged to statuses "2",points $W_{2}=5$.

When belonged to statuses "3",points $W_{3}=5$.

When belonged to statuses "4",points $W_{4}=3$.

There for:

$$
\begin{aligned}
& P_{1}=W_{1} / W=3 / 16, P_{2}=W_{2} / W=5 / 16, \\
& P_{3}=W_{3} / W=5 / 16, P_{4}=W_{4} / W=3 / 16 .
\end{aligned}
$$

- Calculate the state transition probability

The last data did not participate in calculation, because it was not clear which statues was transferred into. According to the table above we could know that:

$$
\begin{aligned}
& W_{11}=1, W_{12}=2, W_{13}=0, W_{14}=0 . \\
& W_{21}=0, W_{22}=1, W_{23}=2, W_{24}=2 . \\
& W_{31}=1, W_{32}=1, W_{33}=1, W_{34}=1 . \\
& W_{41}=0, W_{42}=1, W_{43}=2, W_{44}=0 .
\end{aligned}
$$

Furthermore:

$$
\begin{aligned}
& P=\left[\begin{array}{cccc}
1 / 3 & 2 / 3 & 0 & 0 \\
0 & 1 / 5 & 2 / 5 & 2 / 5 \\
1 / 4 & 1 / 4 & 1 / 4 & 1 / 4 \\
0 & 1 / 3 & 2 / 3 & 0
\end{array}\right] \\
& P_{17}=\left(\frac{3}{16} \frac{5}{16} \frac{5}{16} \frac{3}{16}\right)\left[\begin{array}{cccc}
1 / 3 & 2 / 3 & 0 & 0 \\
0 & 1 / 5 & 2 / 5 & 2 / 5 \\
1 / 4 & 1 / 4 & 1 / 4 & 1 / 4 \\
0 & 1 / 3 & 2 / 3 & 0
\end{array}\right]^{16}
\end{aligned}
$$$$
=\left[\begin{array}{llll}
0.1316 & 0.3070 & 0.3509 & 0.2105
\end{array}\right]
$$ 
The state values of the 16th week was "3",after a transfer, the probability of four states were $0.1316,0.3070,0.3509$, 0.2105 . Because the maximum probability was $P_{33}=0.3509$, it could be predicted that the amount of the sales in the 17th week would be in the range of $450 \leq Q<600$. In fact the amount of the sales of millet company was 520 in the 17th week and it was in the predicted scope. So it could be proved the model had higher prediction accuracy and some practical value.

\section{CONCLUSION}

A key factor that influenced the uncertainty of virtual enterprise was found through the uncertainty analysis of the virtual enterprise supply chain. Millet company market sales situation was predicted through market demand prediction model which based on the Markov chain. And the results of the predictions were in accord with the practical sales. It was illustrated that the method proposed in the paper played a key role in the normal operation of virtual enterprise.

\section{Acknowledgment}

The paper was supported by Liaoning Dr. Research Startup Foundation Project (20150192), Liaoning Natural Science Foundation Project (2016010521-301, 2016010513-301).

\section{References}

[1] Hu Zhenghua. Study on Virtual Enterprise Operation Model[D], Nanjing: Nanjing University of Aeronautics and Astronautics, 2012.

[2] Feng Weidong, Chen Jian. Identifying the Core Competence for Virtual Enterprises: a Qualitative Frame work an[J], Systems Engineeringtheory \& Practice, 2012, 5: 48-54.

[3] Jochen Krautter. Inventory theory: New perspectives for corporate management[J], international journal of production economics, 2015, 59: 129-134.

[4] M.T. Martinez, P. Fouletier, K.H. Park, J. Favrel. Virtual enterprise organization. evolution and control[J], International journal of production economics, 2011, 74: 225-238.

[5] Peng Bin, Zhang Ying, Yuan Qingni. A new IDS Based on Multi-Agent System[J], Technology and Applications, 2011, 44(2): 72-74.

[6] Chris Bauer. Virtual Organization[J], Package Printing, 2013, 7: 26 28.

[7] Pan Haiqing. Research on the Construction, Operation and Evaluation of Green Virtual Enterprise[D], Hefei: HeFei University of Technology, 2016.

[8] Wang Wanshan. Networked manufacturing technology[M], Shenyang: Northeastern University press, 2013.

[9] William B, Werther JR. Structure Driven Strategy and Virtual Organization Design[J], Business Horizon, 2003, 3: 13-18.

[10] N. Viswanadham, Roshan S. Gaonkar. Partner Selection and Synchronized Planning in Dynamic Manufacturing Networks[C], Transactions on Robotics and Automation, IEEE, 2003, 19(3): 117-130.

[11] Wei Yingyi, Chen Zhiyuan. The Agent-based Microscopic Simulation of Traffic[J], Computer engineering and Applications, 2015 (1): 217-230. 